\title{
Mental Health and Self-Esteem among Faculty Nursing Students
}

\author{
Amal Awad Abd El Nabi, Lecturer \\ Psychiatric Nursing and Mental Health, Faculty of Nursing, Damanhour University \\ Nagia Ibrahim Hassan, Lecturer \\ Psychiatric Nursing and Mental Health, Faculty of Nursing, Damanhour University
}

\begin{abstract}
The presence of positive mental health and self-esteem help nursing students to deal with the different events and daily problems and pursue their own goals in life. Consequently they can function effectively in the society. Objective: Determine the relationship between degrees of mental health and self-esteem among faculty nursing students. Setting: The present study was carried out at the faculty of nursing, Damanhour University. Subjects: Three hundred nursing students were randomly selected using simple random sampling method. Tools: Tools used comprised General Health Questionnaire (GHQ), Rosenberg Self-Esteem Scale (RSE) and Socio-demographic and academic characteristics questionnaire. Results: A high significant positive correlation was found between mental health and self-esteem $(P=0.001)$. Male students have higher degree of mental health. Positive correlation was also found between students' satisfaction with choosing nursing as a profession and their mental health and self-esteem ( $P$ : 0.000 and 0.037, respectively). Conclusion: Faculty nursing students in general experience psychological well-being. However, a substantial proportion of them may be on the verge of facing psychological distress. Recommendations: Nursing students' degree of mental health and self-esteem should be assessed regularly, and the counseling services should be organized for students with low degrees of mental health and self-esteem.
\end{abstract}

Keywords: Mental health, Self-esteem, Faculty Nursing students.

\section{Introduction}

Mental health is one of the important aspects of health and considered as an integral component of a person wellbeing $^{(1)}$. Mental health is more than the absence of mental illness. It is a state of well-being in which the individual realizes his/her potentials, can cope with every day stressors, choose optimal solutions to solve problems, can work productively and is able to contribute to the community ${ }^{(2-5)}$. A mentally healthy person is capable of thinking clearly, developing socially and learning new skills with ease ${ }^{(6)}$.

Mental health is a mean by which individuals, groups or large population can enhance their self-esteem as being one of the basic concepts of mental health ${ }^{(7)}$. Selfesteem is a term used to reflect a person's overall evaluation or appraisal of his or her own worth. Individuals with high selfesteem feel they are worthy despite their errors and flows ${ }^{(8)}$. Different studies revealed that nursing students with high self-esteem are able to learn more effectively and establish more profitable relationships. They can make better use of opportunities. They are confident, productive and demonstrate respect and concern for both patients and colleagues. They also have a clearer vision of their life path than those with low self-esteem ${ }^{(5,8,9)}$.

Both positive mental health and high self-esteem are important for student nurses. Regarding positive mental health, it provides a field to improve intellectual and communication skills and leads to emotional growth, resilience and selfesteem. On the other hand, having selfworth or high self-esteem is considered as an asset, critical value and is a major factor 
for creativity and talents to flourish ${ }^{(5)}$. High self-esteem has been reported as one of the necessary characteristics of students joining the nursing profession ${ }^{(10)}$. In addition, selfesteem can provide a positive focus for therapeutic work with clients. It has been linked to the ability to communicate with patients/clients which is a vital part of effective therapy ${ }^{(11,12)}$.

Recent studies conducted to assess mental health of nursing students revealed significantly higher percentage of mental health problems among nursing students than those among the general population $^{(13,14)}$. In the same respect, Kitzrow (2003) concluded that students' mental health problems are getting more serious and complicated and that the need for counseling services has increased ${ }^{(15)}$.

As nursing students are the future nurses of tomorrow, they will be responsible for mental health maintenance and promotion ${ }^{(2)}$. It is crucial for them to be individuals with high self-esteem in order to ensure competent and safe practice. Special attention should be given to their mental health ${ }^{(8)}$. Therefore, this study is conducted at the faculty of nursing, Damanhour University to assess the degrees of mental health and self-esteem among university nursing students and to determine the relation between them.

It is hoped that this study will give more insight on nursing students' mental health and self-esteem which are imperative to identify distress experienced by these students. In addition, determining the contributing factors that lead to their distress, can help in ultimately designing an intervention plan that can be used to improve students' quality of life and reduce their risks of experiencing psychological and mental illness.

\section{Aims of the Study}

This study aims to:
1. Assess the degrees of mental health and self-esteem among faculty nursing students, Damanhour University.

2. Determine the relationship between mental health and self-esteem among faculty nursing students, Damanhour University.

\section{Research Questions:}

1. What are the degrees of mental health and self-esteem among faculty nursing students?

2. Is there a relationship between mental health and self-esteem among faculty nursing students?

\section{Materials and Method}

\section{Materials}

Design: This study follows a descriptive correlational design.

Setting: The study was conducted at the Faculty of Nursing, Damanhour University.

Subjects: The present study was held during the first term of the academic year 2014-2015. The total number of the students enrolled at the faculty of nursing during this academic year amounted to 1200 students along the four years. A representative sample of the students was randomly selected using simple random sampling method.

The EPI-INFO software was used to estimate the sample size of this study, which revealed a minimum sample size of 300 students. This number was distributed along the four academic years as follow; 83 students from the first academic year, 82 students from the second academic year, followed by 90 students from the third academic year and finally, 45 students from the fourth academic year. This is also done in consultation with statistician according to numbers of students in each academic year. Tools: To collect data for this study the following tools were used: 


\section{Tool I: Socio-demographic and Academic Data Sheet}

This tool was developed by the researchers to elicit data such as: age, sex, family income, residency during academic year, year of enrollment, previous academic failure and satisfaction with choosing nursing as a profession.

\section{Tool II: General Health Questionnaire (GHQ)}

This scale was developed by Goldberg \& Williams (1988). It was designed to assess psychological health of the person. It is one of the most widely used psychometric measures in health and psychiatry. It is reliable and valid $^{(16)}$. This scale was designed to assess how a person has been feeling over the past few weeks. It is composed of 12 items; each item is assessed on 4- point likert scale ranging from " 0 " indicating less than usual to " 3 " which means much more than usual. Items with negative statements are scored reversely. Higher scores indicate greater degrees of psychological distress.

\section{Tool III: Rosenberg Self-Esteem Scale $\underline{\underline{\text { RSE}})}$}

The scale was developed by Rosenberg (1965). It is a ten item likert-scale. Items answered on a 4-point-likert scale ranging from "3" which means strongly agree to " 0 " which means strongly disagree. This scale assesses a person's general feelings about himself. It is divided into an equal number of positively and negatively worded items measuring positive and negative selfesteem, with the sum score ranging from 0 to 30 . A higher score indicates higher selfesteem $^{(17)}$.

\section{Method}

- Official permission to conduct this study was obtained from the responsible authorities (Dean of the faculty of nursing).

- Tool (1) was developed by the researchers to cover socio- demographic and academic data of the studied students.

- Tools (2) and (3) were translated into Arabic language and tested for content validity by 5 experts in psychiatric nursing and mental health department at faculty of nursing, Alexandria University. They were proved to be valid.

- A pilot study was carried out on 30 students to check and ensure the clarity and applicability of the tools and estimate the time needed to fill the questionnaire. Students who were included in the pilot study were excluded from the study sample. The pilot study revealed that tools were clear, understood and applicable.

- Reliability test of tools (2) and (3) was done using cronbach's alpha on $10 \%$ of the total sample size (30 students). Tools were proved to be reliable. The values revealed 0.83 for tool (2) and 0.89 for tool (3).

- In order to obtain the required students for data collection, students' numbers were written on papers and caught randomly the first then the second and so on until reaching the final number required from each year. Researchers contacted students' instructors to identify their clinical work settings and schedule of their lectures.

- Data were collected from students either before or after their clinical work or before and after theoretical lecture. Students were gathered on small groups with the researchers who introduced themselves, explained the purpose of the study, obtained students' consent to participate in the study, and reassured them about the anonymity and confidentiality of their responses. Study tools were distributed and instructions about filling them were given. 
Infrequently, data were collected on an individual base from students who missed the group.

- The data were collected during the academic year 2014-2015 along two months, October and November 2014.

\section{Ethical considerations:}

Throughout the study, the following steps were followed:

- The purpose of the study was explained to students.

- Their consent to participate in the study was obtained.

- Data confidentiality was ensured.

- Students' privacy and anonymity were respected.

\section{Statistical Analysis}

After data were collected, it was revised, coded and fed to statistical software SPSS IBM version 20. All statistical analysis were done using two tailed tests and alpha error of 0.05 . $\mathrm{P}$ value less than 0.05 was considered to be statistically significant. All items concerning mental health were summed together and score \% was calculated of the maximum score as follow:

$$
\text { Score } \%=\frac{\text { Actual score }}{\text { Maximum score }} \times 100
$$

The score percentage was later categorized into: Low- moderate- high using the following cutoff points. A student with a score $\%<50 \%$ were considered to have low mental health while those who have a score $\% \geq 75 \%$ were considered to have a high mental health and those in between were considered to have moderate mental health status. Regarding self-esteem, also score \% was calculated after summing the discrete scores for its items and categorized by the same method for mental health.

\section{The following statistical methods were used:}

Descriptive statistics in the form of frequencies and percentages were used to describe the categorical data variables.

Pearson's chi-square test was used to test the association between sample characteristics and their mental health status or self-esteem, but if the distribution cells have a small values, Fisher exact test was preferred.

\section{Results}

Table (1) describes the sociodemographic and academic characteristics of the studied students. It was shown that nearly two thirds $(65 \%)$ of the students were in the age group between 20 to 22 years and about three quarter $(74 \%)$ of them were female. The studied students who had enough family income amounted to $72.3 \%$. As regards students' residency during academic year, 91\% were living with their families. It was observed that $30 \%$ of the studied students were registered in the third year compared to $15.0 \%$ in the fourth year, while the rest were registered in the first and second year $(27.7 \%$ and $27.3 \%$, respectively). Concerning the previous academic failure, the majority of them $(90 \%)$ didn't fail previously. Regarding satisfaction with their choice of nursing as a profession, $64.3 \%$ of students were satisfied with their choice compared to $35.7 \%$ who were not satisfied.

Table (2) illustrates degrees of mental health and self-esteem among the studied students according to their total score percent on General Health Questionnaire and Rosenberg Self-Esteem Scale. It was observed that only $3.3 \%$ of the studied students had high degree of mental health. However, the degrees of mental health varied among them between moderate to low $(54.3 \%$ and $42.4 \%$,respectively).In relation to degree of self-esteem, two thirds of students $(67 \%)$ had moderate degree of self-esteem compared to $18 \%$ and $15 \%$ who 
had high and low degree of self-esteem respectively.

Table (3) reveals the relationship between mental health and self-esteem among studied students. It can be noticed that more than half of the students $(60.0 \%)$ who have high degree of mental health have high degree of self-esteem. A significant positive relation was found between students' mental health and self-esteem $(\mathrm{P}=0.001)$. This means that high degree of mental health is associated with higher degree of self-esteem.

Table (4) exhibits the cumulative results of the relationships between the sociodemographic and academic characteristics of the studied subjects and their degrees of mental health and self-esteem. The table shows that there were a statistical significant relationships between degree of mental health and students' sex, family income, year of enrollment and satisfaction with choosing of nursing as a profession $(\mathrm{P}=0.001, \quad 0.043, \quad 0.000$ and 0.000, respectively). As for the relationship between the socio-demographic and academic characteristics of the studied subjects and their degree of self-esteem, the same table illustrates that the two academic characteristics that having a significant relationship with self-esteem were satisfaction with choosing nursing as a profession and previous academic failure ( $\mathrm{P}=0.037$ and 0.049 , respectively). More details of these relations are shown in table (5).

Table (5) elaborates on the statistical significant relations between students' degrees of mental health and their sociodemographic and academic characteristics. As regard sex, the table shows that male students have better mental health status than female students. More specifically, male students who have high degree of mental health amounted to $7.7 \%$ compared to only $1.8 \%$ of female students with statistical significant difference $(\mathrm{P}=0.001)$.
In relation to family income, $7.5 \%$ of students who claimed that their family income was more than enough have high degree of mental health compared to $0.0 \%$ of students who have not enough income with statistical significant difference, where $\mathrm{P}=0.043$.

Concerning the students' years of enrollment, $4.8 \%$ of first year students had got high degree of mental health, on the contrary, the lowest percent of students who had high degree of mental health $1.2 \%$ were from second year students with statistical significant difference where $\mathrm{P}=0.000$.

As for satisfaction with choosing nursing as a profession, students who were satisfied with their choice of nursing as a profession and had high degree of mental health outnumbered those who were not satisfied ( $4.1 \%$ and $1.9 \%$, respectively). A statistical significant difference was found where $\mathrm{P}=0.000$.

Concerning self-esteem, the same table also illustrates that the percent of high selfesteem among students who were satisfied with their choice of nursing also outnumbered those who were not satisfied (21.2\%, $12.1 \%$ respectively). A statistical significant difference was found where $\mathrm{P}=$ 0.037. Finally, although $86.6 \%$ of students who have previous academic failure have moderate degree of self-esteem, students who did not fail previously have high degree of self-esteem about three times more than students who have previous academic failure $19.3 \%$ and $6.7 \%$, respectively with statistical significant difference $(\mathrm{P}=0.049)$.

\section{Discussion}

Nursing as a career, requires positive mental health and self-esteem among its members. Nursing students are the future professional staff in health care system who play an important role in providing care, treatment and support for patients physically and/or psychologically ${ }^{(18,19)}$. Their degree of mental health and self- 
esteem are expected to affect their ability to face the challenges of their profession. A previous study was conducted on "mental health nursing students' experience of stress" revealed that one-third of student nurses endure mental health problems ${ }^{(20)}$.

The present study indicated that more than half of the studied nursing students have moderate degree of mental health. These results may be explained by the fact that students were interested and motivated to study nursing. As the findings of the present study revealed that about two thirds of students were satisfied and convinced with their choice of nursing career which in turn was significantly correlated with their degrees of mental health. In fact, the degree of satisfaction and interest in the selected field of study will affect person's psychological feelings. Uner et al. (2008) reported that; if students had to study in undesired faculty, they would go toward lack of success and educational failure ${ }^{(21)}$. Also Faragher et al. (2005) reported that job dissatisfaction can be hazardous to individuals' mental health and wellbeing ${ }^{(22)}$. Along the same line, Rafati and Ahmadi (2004) found that students with strong interest in the field of study had significantly less mental health problems ${ }^{(23)}$.

Another possible explanation for these results is the adequate family income which represents a significant factor contributing to mental health in this study. Studied students who have more than enough family income had significant better degree of mental health than those who have not enough income. This result was supported by Pryjmachuk et al. (2008) and Beck et al $(1991)^{(24,25)}$ who concluded that, family income affects students' life style and satisfaction of their needs. However, having financial problem can be one of the important stressors during academic study. Furthermore, a previous research assessing mental health of medical students found that students who have more than enough income had high degree of mental health ${ }^{(26-}$ 28).
Previous results also demonstrated that, a considerable proportion of studied students have low degree of mental health. This seems to suggest that a substantial portion of the students have the predisposition to develop and experience psychological problems. Along the same line, more than half of the students who were not convinced and not satisfied with their decision to choose nursing as a career had got low degree of mental health (table 5 ). This finding could be due to the student's inability to be independent or to achieve autonomous behavior in choosing the intended faculty (autonomy is a basic concept of mental health). In this respect Dalir Z, Mazloum S. (2012) in their study of the relationship between mental health and interest in field of study in nursing and midwifery students, concluded that $32.1 \%$ of the studied subjects had poor mental health and probable psychiatric problems ${ }^{(2)}$.

Regarding self-esteem among the study subjects, the findings of the present study showed that more than two thirds of them had moderate degree. This result may be explained by the effect of students' interest and satisfaction with choosing nursing as the percent of high self-esteem among students who were satisfied with their choice of nursing outnumbered those who were not satisfied (the effect of students' interest and satisfaction was previously mentioned in mental health). Another possible explanation may be due to the academic achievement. Students who did not fail previously had high degree of selfesteem three times more than students who previously failed. It is commonly known that academic achievement gives the student sense of success and satisfaction. Conversely, previous failure will affect them negatively.

This explanation is consistent with the study that was carried out on the effect of time management skills and self-esteem of students on their grade point averages (GPA) and found a positive correlation between self-esteem and academic 
achievement; this means that high selfesteem is accomplished by high academic performance $^{(29)}$. However, although, the percent of high self-esteem is more in students who did not fail previously, large percent of students with previous academic failure have moderate degree of self-esteem. So, one cannot definitely relate the moderate degree of self-esteem to academic achievement. At the same time, one cannot deny the probability of its role in these findings.

The significant positive relationship between the mental health and the selfesteem of students may be attributed to the fact that students who have high self-esteem are stronger and generally have good mental health. On the contrary, negative selfesteem is found to be a risk factor leading to lacking trust in themselves. Therefore, students become unable to handle daily problems which in turn reduce the ability to achieve maximum potential. This could lead to an alarming deterioration in physical and mental well-being ${ }^{(7)}$. This result is consistent with Rafati et al (2014) who found a significant positive relationship between the mental health and self-esteem of the students ${ }^{(5)}$.

Interestingly, sex appears to play a significant role in the degree of mental health among studied students. According to the present study, female students have lower degree of mental health with statistically significant difference noticed between both sexes. This may be understood in the line of the Egyptian cultural beliefs and attitudes in which the feminine role puts a lot of pressure over females due to their obligation in the community as caregivers and family supportive person. Moreover, the high sensitivity level that characterizes the female gender may intensify the feeling associated with faced stressful situations and increases their emotional involvement with patients demonstrating critical diagnoses which consequently affect their mental health. These results proved to be consistent with previous studies which indicated that the prevalence of mental problems was more among female students ${ }^{(21,30,3)}$. While Sepehrmanesh and colleagues' study (2008) concluded that the mental health scores of girls and boys students showed no significant difference ${ }^{(32)}$.

Findings of the present study revealed that year of enrollment affects mental health. The highest percentages of those who have high degrees of mental health were enrolled in the first year and lowest percent were in second year students with statistical significant differences. This result could be attributed to the possibility that first year nursing students viewed nursing as a caring profession that helps people gain better health. It is also viewed as a noble and well-regarded career path which requires strength, patience and compassion. All of these positive views may be reflected in student' own feelings of satisfaction and improve their mental health. A longitudinal study that examined nursing students' perceptions of nursing showed that students considered nursing as a profession based on scientific knowledge and requires expertise in nursing and responsibility ${ }^{(31)}$. This result is in accordance with Lotfi et al. (2010) who conducted a study on psychological health of first year university students and found that $59.2 \%$ of first year nursing students have moderate degree of mental health ${ }^{(33)}$. Conversely, Nerdrum et al. (2006) found that $21 \%$ of first year college students had significant symptoms of psychological distress $^{(34)}$. In relation to second year students, a previous study showed that, the sources of stress are most common in the second year and the reason is heavy professional courses in terms of both theory and practice. These stress factors may cause some negative changes in the psychological health of the students ${ }^{(35)}$. 


\section{Conclusion}

Based on the results of the present study, it can be concluded that; nursing students at Faculty of Nursing, Damanhour University were psychologically healthy in general with moderate degree of mental health and self-esteem. However, considerable proportion of them had been identified as on the verge of facing psychological distress.

\section{Recommendations}

It can be recommended that:

- Faculty nursing students' mental health and self- esteem should be assessed regularly and the counseling services should be organized for students with low degrees of mental health and self-esteem.

- Special attention must be given to nursing students' mental health and self-esteem. Instructors or faculty member should give the nursing students the opportunity to express themselves, provide climate of trust and acceptance that allow students to feel humanity and being respected, focus on students' strength points and guide them how to overcome difficulties they face on a daily base.

- Further study should be done on students' dissatisfaction in relation to year of enrollment.

- Further research is required to study other variables contributing to mental health among university nursing students as ego resilience, selfconcept and self-efficacy. 
Table (1): Distribution of the study subjects according to their socio-demographic and academic characteristics $(\mathbf{N}=\mathbf{3 0 0})$

\begin{tabular}{|c|c|c|}
\hline Student characteristics & $\begin{array}{c}\text { No } \\
(n=300)\end{array}$ & $\%$ \\
\hline \multicolumn{3}{|l|}{ Age (years) } \\
\hline - $18<20$ & 105 & 35.0 \\
\hline - $20-22$ & 195 & 65.0 \\
\hline \multicolumn{3}{|l|}{ Sex } \\
\hline - Male & 78 & 26.0 \\
\hline - Female & 222 & 74.0 \\
\hline \multicolumn{3}{|l|}{ Family income } \\
\hline - More than enough & 53 & 17.7 \\
\hline - Enough & 217 & 72.3 \\
\hline - Not enough & 30 & 10.0 \\
\hline \multicolumn{3}{|l|}{ Residency during academic year } \\
\hline - With family & 273 & 91.0 \\
\hline $\begin{array}{l}\text { - University students' hostellsupervised } \\
\text { house }\end{array}$ & 20 & 6.7 \\
\hline - Relatives $\backslash$ friends & 7 & 2.3 \\
\hline \multicolumn{3}{|l|}{ Year of enrollment } \\
\hline - First & 83 & 27.7 \\
\hline - Second & 82 & 27.3 \\
\hline - Third & 90 & 30.0 \\
\hline - Fourth & 45 & 15.0 \\
\hline \multicolumn{3}{|l|}{ Previous academic failure } \\
\hline - Yes & 30 & 10.0 \\
\hline - $\mathrm{No}$ & 270 & 90.0 \\
\hline \multicolumn{3}{|l|}{$\begin{array}{l}\text { Satisfaction with choosing nursing as a } \\
\text { profession }\end{array}$} \\
\hline - Yes & 193 & 64.3 \\
\hline - $\mathrm{No}$ & 107 & 35.7 \\
\hline
\end{tabular}


Table (2): Degrees of mental health and self-esteem among studied students according to their total scores on each scale $(\mathrm{N}=300)$

\begin{tabular}{|l|cc|cc||}
\hline \multirow{2}{*}{ Degree } & \multicolumn{2}{|c|}{ Mental health } & \multicolumn{2}{c|}{ Self esteem } \\
\cline { 2 - 5 } & No. & $\%$ & No. & $\%$ \\
\hline Low & 127 & 42.4 & 45 & 15.0 \\
Moderate & 163 & 54.3 & 201 & 67.0 \\
High & 10 & 3.3 & 54 & 18.0 \\
\hline
\end{tabular}

Total mental health and self-esteem scoring keys:

High: Score $\% \geq 75 \% \quad$ Moderate: Score $\% 50 \%-<75 \% \quad$ Low: Score $\%<50$

Table (3): Relationship between mental health and self-esteem among studied students

\begin{tabular}{|c|c|c|c|c|c|c|c|}
\hline \multirow{3}{*}{ Self esteem } & \multicolumn{6}{|c|}{ Mental Health } & \multirow{3}{*}{ MCP } \\
\hline & \multicolumn{2}{|c|}{ Low } & \multicolumn{2}{|c|}{ Moderate } & \multicolumn{2}{|c|}{ High } & \\
\hline & No & $\%$ & No & $\%$ & No & $\%$ & \\
\hline Low & 36 & 28.3 & 8 & 4.9 & 1 & 10.0 & \\
\hline Moderate & 81 & 63.8 & 117 & 71.8 & 3 & 30.0 & $0.001 *$ \\
\hline High & 10 & 7.9 & 38 & 23.3 & 6 & 60.0 & \\
\hline
\end{tabular}

MCP: P value based on Mont Carlo exact probability

*Significant value at $\mathrm{P}<0.05$

Table (4): Cumulative results of the relationship between students' study variables and their socio-demographic and academic characteristics that are significantly related

\begin{tabular}{||l|c|c||}
\hline $\begin{array}{l}\text { Socio-demographic and } \\
\text { academic characteristics }\end{array}$ & $\begin{array}{l}\text { Mental health } \\
\text { (MCP values) }\end{array}$ & $\begin{array}{c}\text { Self esteem } \\
\text { (MCP values) }\end{array}$ \\
\hline Sex & $0.001^{*}$ & 0.542 \\
\hline Family income & $0.043^{*}$ & 0.139 \\
\hline Year of enrollment & $0.000^{*}$ & 0.178 \\
\hline Previous academic failure & 0.176 & $0.049^{*}$ \\
\hline $\begin{array}{l}\text { Satisfaction with choosing } \\
\text { nursing as profession }\end{array}$ & $0.000^{*}$ & $0.037^{*}$ \\
\hline
\end{tabular}

*Significant value at $\mathrm{P}<0.05$ 
Table (5): Detailed results of the relation between students' study variables and their socio -demographic and academic characteristics that are significantly related

\begin{tabular}{|c|c|c|c|c|c|c|c|c|}
\hline \multirow{3}{*}{\multicolumn{2}{|c|}{$\begin{array}{l}\text { Socio-demographic and } \\
\text { academic characteristics }\end{array}$}} & \multicolumn{6}{|c|}{ Mental health } & \multirow{3}{*}{$\begin{array}{l}\text { MCP } \\
\text { values }\end{array}$} \\
\hline & & \multicolumn{2}{|c|}{ Low } & \multicolumn{2}{|c|}{ Moderate } & \multicolumn{2}{|c|}{ High } & \\
\hline & & No. & $\%$ & No. & $\%$ & No. & $\%$ & \\
\hline \multirow{2}{*}{ Sex } & Male & 18 & 23.1 & 54 & 69.2 & 6 & 7.7 & \multirow{2}{*}{$0.001 *$} \\
\hline & Female & 109 & 49.1 & 109 & 49.1 & 4 & 1.8 & \\
\hline \multirow{3}{*}{ Family income } & $\begin{array}{l}\text { More } \\
\text { than } \\
\text { enough }\end{array}$ & 16 & 30.2 & 33 & 62.3 & 4 & 7.5 & \multirow{3}{*}{$0.043 *$} \\
\hline & Enough & 93 & 42.9 & 118 & 54.4 & 6 & 2.8 & \\
\hline & $\begin{array}{l}\text { Not } \\
\text { enough }\end{array}$ & 18 & 60.0 & 12 & 40.0 & 0 & 0.0 & \\
\hline \multirow{4}{*}{ Year of enrollment } & First & 21 & 25.3 & 58 & 69.9 & 4 & 4.8 & \multirow{4}{*}{$0.000 *$} \\
\hline & Second & 31 & 37.8 & 50 & 61.0 & 1 & 1.2 & \\
\hline & Third & 58 & 64.4 & 28 & 31.1 & 4 & 4.4 & \\
\hline & Fourth & 17 & 37.8 & 27 & 60.0 & 1 & 2.2 & \\
\hline \multirow{5}{*}{$\begin{array}{l}\text { Satisfaction with } \\
\text { choosing nursing as } \\
\text { a profession }\end{array}$} & Yes & 63 & 32.6 & 122 & 63.2 & 8 & 4.1 & \multirow[b]{2}{*}{$0.000 *$} \\
\hline & No & 64 & 59.8 & 41 & 38.3 & 2 & 1.9 & \\
\hline & & \multicolumn{6}{|c|}{ Self esteem } & \\
\hline & & \multicolumn{2}{|c|}{ Low } & \multicolumn{2}{|c|}{ Moderate } & \multicolumn{2}{|c|}{ High } & \\
\hline & & No. & $\%$ & No. & $\%$ & No. & $\%$ & \\
\hline \multirow{2}{*}{$\begin{array}{l}\text { Satisfaction with } \\
\text { choosing nursing as } \\
\text { a profession }\end{array}$} & Yes & 23 & 11.9 & 129 & 66.8 & 41 & 21.2 & \multirow[b]{2}{*}{$0.037 *$} \\
\hline & No & 22 & 20.6 & 72 & 67.3 & 13 & 12.1 & \\
\hline \multirow{2}{*}{$\begin{array}{l}\text { Previous academic } \\
\text { failure }\end{array}$} & Yes & 2 & 6.7 & 26 & 86.6 & 2 & 6.7 & \multirow{2}{*}{$0.049 *$} \\
\hline & No & 34 & 15.9 & 175 & 64.8 & 52 & 19.3 & \\
\hline
\end{tabular}

*Significant value at $\mathrm{P}<0.05$ 


\section{References}

1. Ganji H. Mental health. $3^{\text {rd }}$ ed. Tehran, Iran: Arasbaran Publisher, 2000.

2. Dalir Z, Mazloum S. Relationship between mental health and interest in field of study in nursing and midwifery students. Life Science Journal 2012; 9(3): 1916-21.

3. Draganović S. Mental health and coping strategies of Bosnian immigrants in Switzerland. Journal of Philosophy, Sociology, Psychology and History 2011; 10(2): $195-202$.

4. Forouhari S, Ghaemi S, Tobesaz P, and Sharif F. Relation between religious beliefs and mental health among students of Hazrat-e-Fatemeh nursing and midwifery college Shiraz-Iran. International Journal of Management and Humanity Sciences 2014; 3(2): 1459-62.

5. Rafati F, Rafati SH, Mashayekhi F, Pilehvarzadeh M, Mashayekh M.The comparison of the mental health and self-esteem in the gifted and normal adolescents of high schools in Jiroft City in the year 2012-2013. International Journal of Current Research and Academic Review 2014; 2(6): 220-28.

6. Zulkefly N, Baharudin R. Using the 12item general health questionnaire (GHQ-12) to assess the psychological health of Malaysian college students. Global Journal of Health Science 2010; 2(1): 73-80.

7. Mann M, Hosman C, Schaalma H, Vries N. Self-esteem in a broad-spectrum approach for mental health promotion. Health Education Research Theory \& Practice 2004; 19(4): 357-72.

8. Hamoud S, El Dayem S, Ossman L. The Effect of an assertiveness training program on assertiveness skills and self-
Esteem of faculty nursing students. Journal of American Science 2011; 7(12): 1085-1096.

9. Khalil A, Abou-Hashish M, Dawood E. Coeducation versus single sex education: impact on self Esteem and academic achievements among nursing' students. Journal of American Science 2011; 7(12): 176-84.

10. Horn H, \& Holzemer WL Characteristics of Israeli women studying nursing compared to women studying education and engineering. Journal of Nursing Education1991; 30(9): $411-8$.

11. Carson, J., Harman, K., Webb, S., Kimonis, E., Kuipers, E. Assessing and measuring self-esteem in mental health: a comparison of scales in current use. Journal of Mental Health and Learning Disabilities Care 2001; 4(10): 336-9.

12. Edwards D, Burnard P, Bennett K, Hebden U. A longitudinal study of stress and self-esteem in student nurses. Journal of Nurse Education Today. 2010; 30: 78-84.

13. Bernhardsdottir J, Vilhjalmsson R. Psychological distress among university female students and their need for mental health services. Journal of Psychiatric and Mental Health Nursing, 2013; 20: 672-8.

14. Stallman H.M. Psychological distress in university students: a comparison with general population data. Journal of Australian Psychologist 2010; 45: 24957.

15. Kitzrow M.A. The mental health needs of today's college students: challenges and recommendations. NASPA Journal 2003; 41: 167-81.

16. Goldberg D. P, Williams P. A. A user's guide to the General Health 
Questionnaire. Windsor, UK: NFERNelson; 1988.

17. Rosenberg M. Society and adolescent self-image. Princeton NJ: Princeton University Press, 1965.

18. Parsa P. A study on the prevalence of stress and mental disorders in students of nursing and midwifery faculty. Journal of Fundamental of Mental Health 2000; 2 (5,6): 25-30.

19. Carveth JA, Gesse T, Moss N. Survival strategies for nurse- midwifery students. Journal of Nurse-Midwifery. 1996; 41(1): 50-4.

20. Freeburn M, Sinclair M. Mental health nursing students' experience of stress: burdened by a heavy load. Journal of Psychiatric and Mental Health Nursing 2009; 16: 335-42.

21. Uner S, Ozcebe H, Telatar TG, Tezcan S. Assessment of mental health of university students with GHQ-12. Turkish Journal of Medical Science 2008; 38 (5): 437-46.

22. Faragher EB, Cass M, Cooper CL. The relationship between job satisfaction and health: a meta-analysis. Journal of Occupational and Environmental Medicine 2005; 62(2): 105-12.

23. Rafati F, Ahmadi J. Depression in nursing students of Shiraz University of Medical Sciences. Journal of Research in Medical Sciences 2004; 9(1): 39-41.

24. Pryjmachuk S, Richards DA. Predicting stress in preregistration midwifery students attending a university in Northern England. Journal of Midwifery 2008; 24(1): 108-22.

25. Beck DL, Srivastava R. Perceived level and sources of stress in baccalaureate nursing students. Journal of Nursing Education 1991; 30(3): 127-33.
26. Shariati M, Yunesian M, HomayounVash J. Mental health of medical students: a cross-sectional study in Tehran. Psychological Reports 2007; 100(2): 346-54.

27. Lora E, Chaparro J. The conflictive relationship between satisfaction and income, 2008; 2-51. Available at: https://www.google.com.eg/?gws rd=ss

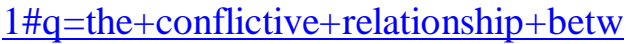
een+satisfaction+and+income.

28. Stevenon B, Wolfers J. Subjective wellbeing and income: is there any evidence of satisfaction. American Economic Review 2013; 103(3): 598-604.

29. Eid N, Safan S, Diab G. The Effect of time management skills and self Esteem of students on their grade point averages (GPA).Journal of Nursing and Health Science 2015; 4(1): 82-8.

30. Buerhaus P, Donelan C, Norman L, Dittus R. Nursing students perceptions of a career in nursing and impact of a national campaign designed to attract people into the nursing profession. Journal of Professional Nursing 2005; 21(2): 75-83.

31. AlJarrah I. Associate nursing students' perceptions toward nursing profession in Jordan. European Scientific Journal 2013; 9(6): $147-66$.

32. Sepehrmanesh Z, Ahmadvand A, Yavariparvin. Assessing the mental health of adolescents in kashan, 2004. Iranian Journal of epidemiology. 2008; 4(2): 43-9.

33. Lotfi M A, Minian AH, Ghomizadeh A, Nourani F. A study on psychological health of first year university students in Iran. Iranian Journal of Psychiatry and Behavioral Sciences 2010; 3(2): 47-51. 
34. Nerdrum P, Rustøen T. \& Rønnestad M. Student psychological distress: a psychometric study of 1750 Norwegian 1st-year undergraduate students. Scandinavian Journal of Educational Research 2006; 50: 95-109.
35. Altiok H, Üstun B. The stress sources of nursing students. Journal of Educational Sciences: Theory \& Practice 2013; 13(2): 760-6. 